\title{
Kasvihuoneen jäähdytyksellä parempaan ilmastoon ja satoon
}

\author{
Liisa Särkkä, Eeva-Maria Tuhkanen, Tiina Hovi-Pekkanen ja Risto Tahvonen \\ MTT Kasvintuotannon tutkimus Puutarhatuotanto, Toivonlinnantie 518, 21500 Piikkiö, \\ liisa.sarkka@mtt.fi
}

\section{Tiivistelmä}

Ympärivuotisessa kasvihuonetuotannossa kesäajan ja talvikauden sadot ovat lähes saman suuruiset, vaikka talven tuotanto on lähes pelkän tekovalon varassa. Kesällä tuotannon tehokkuutta rajoittaa auringon kasvihuoneita liikaa lämmittävä vaikutus, jonka takia tuuletusluukkuja joudutaan pitämään auki. Sen seurauksena kasvulle oleellisen hiilidioksidin määrä kasvihuoneessa vähenee, mikä osaltaan rajoittaa kasvua.

MTT:n tutkimuksissa kasvihuoneen olosuhteita säädettiin jäähdytyslaitteiston avulla. Lämpötilaa, hiilidioksidipitoisuutta ja ilman suhteellista kosteutta pystyttiin hallitsemaan avaamatta tuuletusluukkuja, paitsi kesän kuumimpina iltapäivän tunteina. Tällaista kasvihuonetta kutsutaan puolisuljetuksi kasvihuoneeksi (semi-closed greenhouse, engl.).

Viljelykokeita tehtiin kurkulla, tomaatilla ja leikkoruusulla. Kokeissa verrattiin puolisuljetun ja perinteisen luukkutuuletushuoneen (avoin huone) olosuhteissa kasvatettujen kasvien sadon määrää ja laatua toisiinsa. Lisäksi tutkittiin kasvustojen rakennetta ja yhteyttämisaktiivisuutta mahdollisina selittävinä tekijöinä saaduille tuloksille.

Kurkun ja tomaatin kesäsadot suurenivat, ruusun sadon laatu parani ja kasvien rakenne muuttui puolisuljetussa huoneessa verrattuna avoimeen huoneeseen. Kasvihuoneen korkea hiilidioksidipitoisuus ja sitä kautta parantunut lehtien yhteyttäminen selittivät suurimmaksi osaksi saadut tulokset. Lisäksi havaittiin, että puolisuljetussa kasvihuoneessa tulee viljelyolosuhteita kehittää edelleen.

\section{Asiasanat}

Kurkku, puolisuljettu kasvihuone, ruusu, tomaatti, viljelytekniikka, yhteyttäminen 


\section{Johdanto}

Kasvihuoneen jäähdytystä on käytetty maapallon kuumissa maissa jo vuosikymmeniä. Perinteisessä jäähdytysmenetelmässä ulkoilma pakotetaan kosteiden seinämien läpi, jolloin sisään menevä ilma on jäähtynyt ja sen hiilidioksidipitoisuus on sama kuin ulkoilmassa. Viime vuosina kasvihuoneen jäähdytysmenetelmiä on kehitetty Euroopassa, koska jopa Suomessa kesäaikaan huoneen lämpötila nousee liian korkeaksi. Uusille menetelmille on yhteistä, että tuuletusluukkuja pyritään pitämään kiinni mahdollisimman paljon, jolloin kasvihuoneessa voidaan ylläpitää korkeaa hiilidioksidipitoisuutta. Tällaista huonetta kutsutaan puolisuljetuksi kasvihuoneeksi.

Tämän MTT Piikkiössä tehdyn tutkimuksen tarkoituksena oli verrata puolisuljetussa kasvihuoneessa viljeltyjen kasvien sadon märää ja laatua avoimessa kasvihuoneessa viljeltyjen kasvien satoon. Avoimeksi kasvihuoneeksi kutsuttaan perinteistä kasvihuonetta, jossa ilmaa viilennetään avaamalla kattoluukkuja. Koekasveina olivat leikkoruusu, tomaatti ja kurkku. Koska puolisuljetussa kasvihuoneessa olosuhteita voidaan hallita, hypoteesinä oli, että sadon määrä ja laatu paranevat. Selittävinä tekijöinä tutkittiin mm. kasvien rakennetta ja yhteyttämistehokkuutta. Tässä artikkelissa esitetään vain tutkimuksen keskeisimpiä tuloksia. Tarkemmat tulokset ovat julkaisuissa Särkkä ym. (2006, 2008) ja Luomala ym. (2008).

\section{Aineisto ja menetelmät}

Leikkoruusulajiketta 'Happy Hour' viljeltiin noin 1,5 vuotta. Tarkemmat viljelymenetelmät on julkaistu aikaisemmin Särkkä ym. (2008). Oleellisinta ilmaston hallinnassa olivat avoimen ja puolisuljetun huoneen hiilidioksidipitoisuus, jäähdytyksen alkamislämpötila puolisuljetussa huoneessa sekä tuuletusluukkujen avautumislämpötila molemmissa huoneissa. Hiilidioksidia syötettiin puhtaana kaasuna (Aga Oy) 20 tuntia/vrk 800 ppm, kun globaali säteily oli yli $400 \mathrm{~W} / \mathrm{m}^{2}$ ja 600 ppm, kun säteily oli alle $400 \mathrm{~W} / \mathrm{m}^{2}$. Hiilidioksidin syöttö lopetettiin, kun luukut avoimessa huoneessa avautuivat $30 \%$. Jäähdytyskone alkoi toimia $25,5{ }^{\circ} \mathrm{C}$ :ssa ja avoimessa huoneessa tuuletusluukut avautuivat 26 ${ }^{\circ} \mathrm{C}$ :ssa. Jos jäähdytyskoneen teho ei riittänyt ja lämpötila nousi yli $28{ }^{\circ} \mathrm{C}$, tuuletusluukkuja avattiin enimmillään $15 \%$.

Tomaattilajiketta 'Encore' viljeltiin helmikuusta syyskuun. Tarkemmat viljelymenetelmät löytyvät julkaisusta Särkkä ym. (2008). Hiilidioksidipitoisuus oli 800 ppm. Avoimen huoneen hiilidioksidin syöttö lopetettiin, kun luukut avautuivat yli 30 \%. Jäähdytys puolisuljetussa huoneessa ja tuuletus avoimessa huoneessa alkoivat $24{ }^{\circ} \mathrm{C}$ :ssa. Puolisuljetun huoneen luukut avautuivat $26{ }^{\circ} \mathrm{C}$ :ssa enimmillään $15 \%$.

Kurkkulajiketta 'Cumuli' viljeltiin kaksi kesää. Tarkemmat viljelymenetelmät on julkaistu Särkkä ym. (2008). Hiilidioksidipitoisuuden tavoitearvo oli 1000 ppm. Syöttö lopetettiin, kun avoimen huoneen tuuletusluukut avautuivat yli $30 \%$. Jäähdytys puolisuljetussa huoneessa ja tuuletus avoimessa huoneessa alkoivat $26{ }^{\circ} \mathrm{C}$ :ssa. Luukut avautuivat puolisuljetussa huoneessa enimmillään $28 \%$ jos ilman lämpötila nousi yli $28^{\circ} \mathrm{C}$.

Kaikkien kokeiden koejärjestelynä oli täydellisesti satunnaistettujen lohkojen koe, jossa lohkot olivat pesiytyneet käsittelyihin. Tilastolliset testaukset tehtiin SAS 9.13 ohjelmiston Mixed proseduurilla.

Kokeiden kasvien sadot laskettiin, laatuluokiteltiin ja punnittiin. Vihanneskasveista mitattiin tuore- ja kuivapainot, varren pituus, lehtipinta-ala lehtiplanimetrilla (LI-3100 Li-Cor Inc., Lincoln, USA) ja lehtien lukumäärä viljelyn aikana ja/tai lopussa. Ruusulta tuore- ja kuivapainoja sekä lehtipinta-aloja mitattiin jokaisessa satojaksossa. Kaikilta kasveilta mitattiin yhteyttämisaktiivisuus (LI-6400, Li-Cor Inc. Lincoln, USA). Tarkemmat menetelmät löytyvät Särkkä ym. (2008).

\section{Tulokset}

Ruusun sadon laatu parani puolisuljetussa huoneessa verrattuna perinteiseen huoneeseen, etenkin kesäkuukausina (Kuvio 1) (Särkkä ym. 2008). Laatutekijöinä olivat sadon paino ja pituusluokat. Kukkavarsien lukumäärissä ei ollut eroja. Jäähdytyskone oli käytössä maaliskuun ja marraskuun välisenä aikana.

Yhteyttämismittausten hiilidioksidin vastekäyrän mukaan molemmissa huoneissa ruusunlehdet yhteyttivät yhtä hyvin samassa hiilidioksidipitoisuudessa. Koska puolisuljetussa huoneessa 
hiilidioksidipitoisuus pysyi avointa huonetta korkeampana, myös yhteyttämisaktiivisuus oli korkeampi. Se selittää ruususadon laadun paranemista.

Hollantilaisessa kokeessa ruusun sadon määrä kasvoi suljetussa kasvihuoneessa, toisin kuin meidän kokeessa (Medema 2007). On mahdollista, että kokeemme huoneilman olosuhteet eivät olleet parhaat mahdolliset kyseiselle lajikkeelle. Toisaalta, avoimen huoneen olosuhteet olivat varsin hyvät suurpainesumujen ja varjostusverhojen takia, jotka lievittivät korkean globaalisäteilyn aiheuttamaa ilmastostressiä.
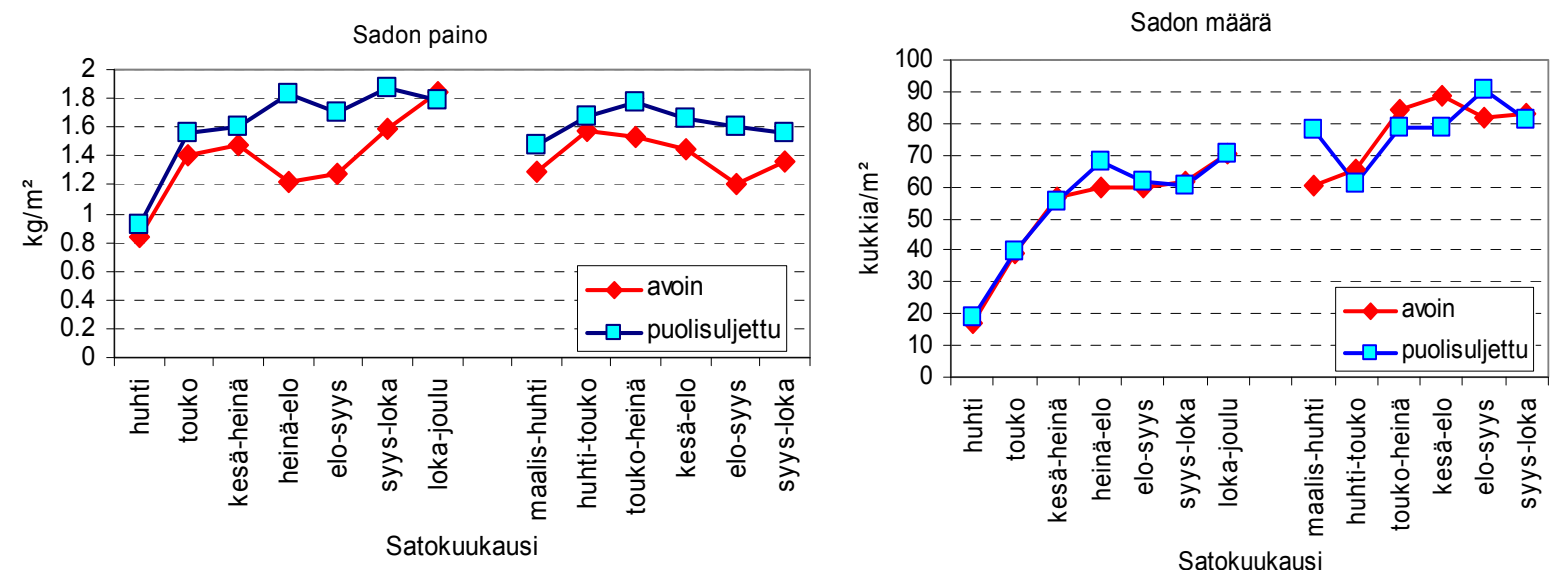

Kuvio 1. Ruusun satotulokset satokuukausittain puolisuljetussa ja avoimessa kasvihuoneessa.

Tomaatin kesäkauden sato oli parempi puolisuljetussa kuin avoimessa kasvihuoneessa. Ensimmäisen laatuluokan kesäsato (vko 23-35) oli puolisuljetussa huoneessa $208 \mathrm{kpl} / \mathrm{m}^{2}$ ja avoimessa huoneessa $190 \mathrm{kpl} / \mathrm{m}^{2}(\mathrm{P}<0,05)$ (Särkkä ym. 2008). Keväällä sadon määrissä ei ollut eroja. Keväällä jäähdytyslaitteistoa ei tarvittu juuri lainkaan, mikä selittää erojen puuttumisen tänä aikana. Kesällä liian kuumassa ja kuivassa ilmassa tomaatin kukkien pölytys vaikeutuu (Peet ym. 2003).

Myös tomaatilla, kuten ruusulla, yhteyttäminen oli tehokkaampaa korkeamman hiilidioksidipitoisuuden puolisuljetussa huoneessa kuin alhaisemman pitoisuuden avoimessa huoneessa. Loppukesällä ero yhteyttämisaktiivisuudessa huoneiden välillä pieneni, mikä oli osoitus lehtien sopeutumisesta korkeaan hiilidioksidipitoisuuteen puolisuljetussa huoneessa. Tämä tulos osoittaa, että tomaatin viljelyoloja pitää kehittää tehokkaimman tuotannon ylläpitämiseksi pitkässä viljelyjaksossa.
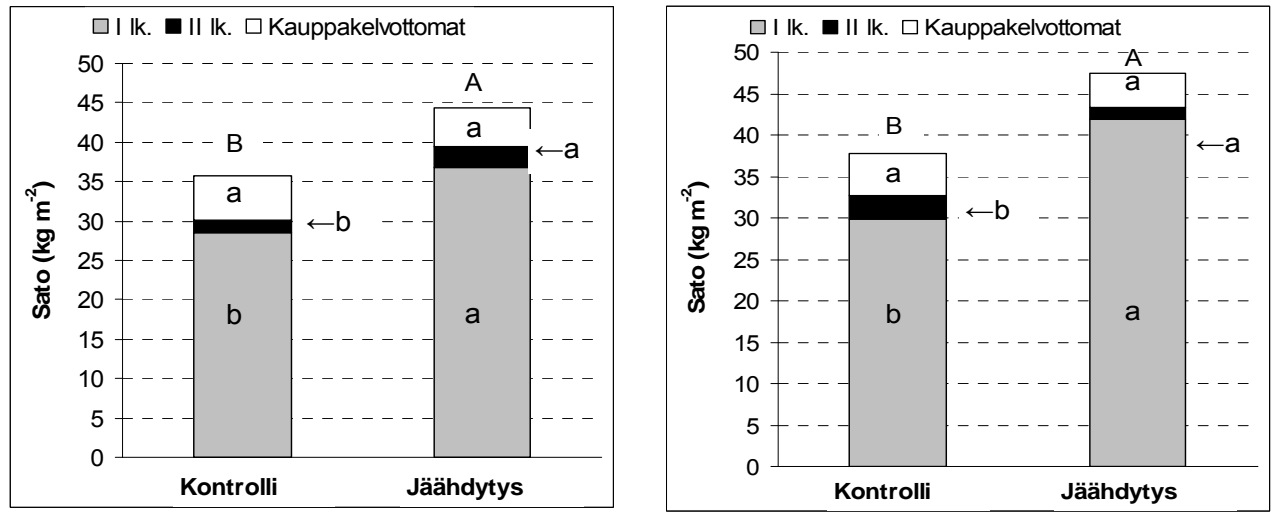

Kuvio 2. Kurkun sadot laatuluokittain avoimessa (kontrolli) ja puolisuljetussa (jäähdytys) kasvihuoneessa kahtena eri kesänä, vasemmalla kesä 1,oikealla kesä 2. Tilastollinen ero kussakin laatuluokassa on osoitettu eri kirjaimin, kokonaissadon vertailu isoin kirjaimin $(\mathrm{P}<0,05)$. 
Kurkun kesäviljelyssa satojen määrät nousivat selvästi puolisuljetussa huoneessa verrattuna avoimeen huoneeseen (Kuvio 2) (Särkkä ym. 2006, 2008) . Ensimmäisenä kesänä sadonlisä ei ollut yhtä suuri kuin toisena. Toinen koekesä oli hyvin aurinkoinen ja lämmin, jolloin hyöty jäähdytyksestä näkyi vielä ensimmäistä kesää suurempana sadonlisänä.

Kurkkukasvin rakenne muuttui puolisuljetussa huoneessa verrattuna avoimeen huoneeseen. Puolisuljetussa huoneessa nivelväli oli pidempi, lehtien lukumäärä pienempi ja lehtipinta-ala suurempi kuin avoimessa huoneessa $(\mathrm{P}<0,05)$ (Särkkä ym. 2006). Lehtipinta-alan kasvu oli edullista kasvien hiilensidonnan kannalta, sillä suurempi yhteyttävä pinta-ala mahdollisti suuremman kokonaissnettofotosynteesin. Ylälehtien suurempi pinta-ala oli myös kasvin kasvun kannalta eduksi, sillä ylälehdet yhteyttivät aktiivisimmin (Luomala ym. 2008). Kurkun sadonlisä johtui vähentyneestä hedelmien abortoitumisesta. Abortoitumisen vähentymiseen vaikuttivat puolisuljetun huoneen tasaisempi lämpötila, erityisesti äärimmäisten lämpöhuippujen poisjäänti, sekä myös kasvien paremmat hiilihydraattivarannot. Tarjolla olevien yhteyttämistuotteiden määrä vaikutti hedelmänalkujen kehittymiseen. Puolisuljetun huoneen korkeampi hiilidioksidipitoisuus (Kuvio 3) vaikutti kasvuun nostamalla yhteyttämisnopeutta (Särkkä ym. 2008).

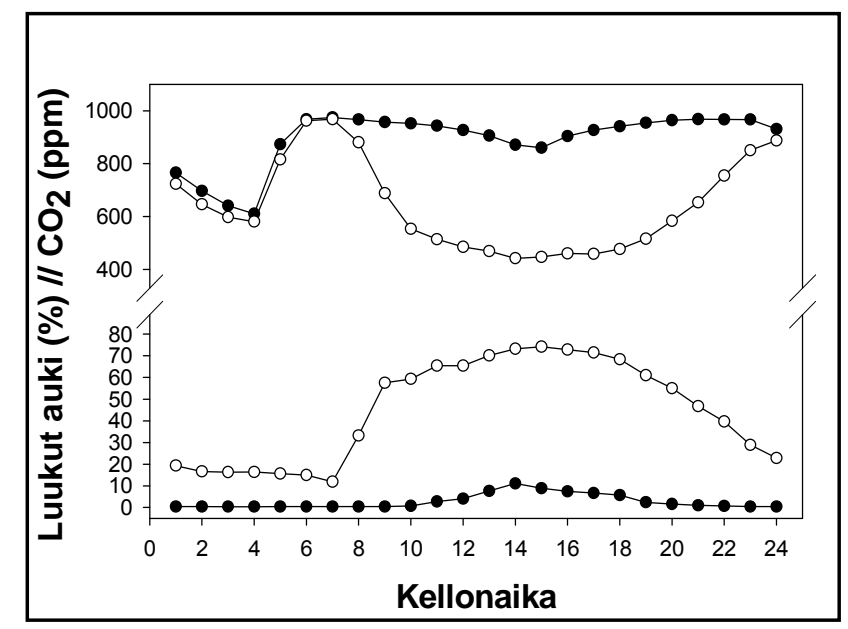

Kuvio 3. Ilman hiilidioksidipitoisuus ja luukkujen aukioloaste puolisuljetussa (suljettu ympyrä) ja avoimessa (avoin ympyrä) kasvihuoneessa elokuun kellonaikojen keskiarvona. Viljelykasvina oli kurkku.

\section{Johtopäätökset}

Tulokset osoittivat, että myös Suomen ilmasto-olosuhteissa kasvihuoneen jäähdytys parantaa kasvien sadon määrää ja laatua. Lisäksi tutkimus osoitti, että kasvihuoneolosuhteiden optimointi ei ole vielä valmis. Kun kasvihuoneen olosuhteita pystytään hallitsemaan uusilla jäähdytysmenetelmillä, olosuhteiden räätälöinti kasvikohtaisesti on parantunut oleellisesti. Tutkimusta tarvitaan niin optimaalisten hiilidioksidipitoisuuksien kuin lämpötilan, tekovalon, kastelun ja lannoituksen suhteen. Jäähdytysmenetelmiä on myös kehitettävä entistä energiatehokkaammiksi ja energiaa talteen ottaviksi, jotta kasvihuoneen kokonaisenergiankulutusta voidaan vähentää ja siten ylläpitää kannattava tuotanto kotimaassa.

\section{Kirjallisuus}

Luomala, E-M., Särkkä, L. \& Kaukoranta, T. 2008. Altered plant structure and greater yield of cucumber grown at elevated $\mathrm{CO}_{2}$ in a semi-closed greenhouse. Acta Horticulturae 801: 1339-1345.

Medema, D. 2007. Koelen roos verhoogt productie en kwaliteit. Vakblad voor de Bloemisterij 51/52: 56-57.

Peet, M., Sato, S., Clemente, C. \& Pressman, E. 2003. Heat stress increases sensitivity of pollen, fruit and seed production in tomatoes (Lycopersicon esculentum Mill.) to non-optimal vapour pressure deficits. Acta Horticulturae 618: 209-215.

Särkkä, L. E., Hovi-Pekkanen, T., Kaukoranta, T.,Tahvonen, R. \& Huttunen, J. 2006. Greenhouse Cooling in Summer in Finland - Preliminary Results of Climate Control and Plant Response. Acta Horticulturae 719: 439-445.

Särkkä, L., Luomala E-M., Hovi-Pekkanen, T., Kaukoranta, T., Tahvonen, R., Huttunen, J. \& Alinikula, M. 2008. Kasvihuoneen jäähdytyksellä parempaan ilmastoon ja satoon. Maa- ja elintarviketalous 122: $102 \mathrm{~s}$. 